\title{
CERVEJA EGÍPCIA? EDUCAÇÃO PARA AS RELAÇÕES ÉTNICO-RACIAIS (ERER) NA FORMAÇÃO DOCENTE EM QUÍMICA
}

Eliete Lucia Silva ${ }^{a}$, Marysson Jonas Rodrigues Camargoa e Anna Maria Canavarro Benite ${ }^{a, *}$,(1)

anstituto de Química, Universidade Federal de Goiás, 74690-900 Goiânia - GO, Brasil

Recebido em 10/05/2021; aceito em 13/09/2021; publicado na web em 13/10/2021

EGYPTIAN BEER? EDUCATION FOR ETHNIC-RACIAL RELATIONS (ERER) IN TEACHER FORMATION IN CHEMISTRY. This work was carried out in a Higher Education Institution (IES), in the State of Goiás, in the Chemistry Degree course, aiming at the implementation of Law 10639/03. The context discussed herein is the chemical knowledge of African and diasporic matrices from Ancient Egypt in the development and production of beer. In order to subsidize teachers in initial formation with strategies in the classroom for an anti-racist education, taking into account the contribution of African people in the constitution of the country. It is an action research and its development happened through a Pedagogical Intervention (IP) with the theme: Ancient Egypt, Beer and Chemistry. The results were collected through audio recording and analyzed using the Conversation Analysis technique. Our results have shown that it is possible to talk about African history and culture, in a chemistry class in the initial chemistry teacher training course, making an epistemic shift in the curriculum, taking previously silenced knowledge to school, such as the history and culture of African peoples.

Keywords: beer; law 10639/03; initial training; african matrix.

\section{INTRODUÇÃO}

O tráfico negreiro brasileiro:

foi uma das maiores, senão a maior distorção histórica da humanidade, implicando a vida dos descendentes de escravizados até os dias atuais. A distorção histórica, neste contexto, é a desigualdade iniciada por esta concepção de diferença como sinônimo de inferioridade, perpetuada através dos anos (p. 398). ${ }^{1}$

Nesse sentido, o processo de inferiorização se deu a partir da centralidade da raça como categoria fictícia, pois biologicamente inexiste, utilizada como forma de classificar os seres humanos, a datar de 1684. Foi, portanto, uma das tecnologias do colonialismo europeu para a subordinação e aniquilação de autóctones americanos, africanos traficados a qual foi utilizada para naturalizar desigualdades e legitimar a segregação e o extermínio de grupos sociologicamente considerados minoritários. Assim, o racismo é uma construção histórica, cultural, social, ideológica e estrutural que remete a atitudes ou comportamentos de exclusão e à injustiça social. ${ }^{1,2-4}$

Lélia González defendeu que o racismo se constitui como ciência branca e patriarcal, visto que o modelo valorizado e universal é o homem branco, legitimando como superiores as cosmovisões eurocêntricas, conferindo ao pensamento moderno ocidental a exclusividade de conhecimento válido, impondo-o como dominante e, assim, inviabilizando outras experiências do saber. ${ }^{3}$ Disso resulta a ideia de hierarquização de saberes como produto da classificação racial: quem possui poder social possui o poder epistêmico. ${ }^{3} \mathrm{~A}$ manutenção desse estado de coisas passa necessariamente pela escola, aparelho ideológico do Estado, pois o currículo nela materializado enquanto artefato social e político é produto de seleção cujas decisões são tomadas em meio à influências assimétricas. ${ }^{5}$ Logo, o currículo se torna eurocêntrico, negligenciando o papel histórico de negros e negras na edificação do Brasil, subrepresentando e até mesmo

*e-mail: anna@ufg.br invizibilizando os conhecimentos e as culturas desse segmento e, por fim, fomentando práticas racistas no interior da sala de aula. ${ }^{6}$

Em contrapartida, é preciso que se desenvolva uma educação antirracista para qual são necessárias estratégias de ensino que considerem todas as culturas e a diversidade presentes na sociedade brasileira. Defendemos que o deslocamento epistêmico do currículo pode ser uma via para essa seara, por meio do qual esperamos que se possa superar as perspectivas eurocêntricas de conhecimentos de um passado (e presente) repleto de contribuições de outros povos. ${ }^{7}$

Com a luta dos movimentos negros para a inclusão da história africana no currículo escolar brasileiro, a Lei 10.639/03 foi promulgada tornando obrigatória a inserção no currículo dos ensinos fundamental e médio das redes publica e privada do país. Essa proposta de mudança tem o objetivo de valorizar e reconhecer a presença do negro e negra na construção histórica, social, econômica e cultural do país. Mas a Lei sozinha não resolve séculos de apagamento e invisibilidade. Existe a necessidade de que a formação inicial de professores desenvolva essa temática, uma vez que serão esses docentes que deverão ser capazes de atuar em sala de aula frente ao racismo e suas formas de concretização. Defendemos que para essa operacionalização nas instituições escolares, é necessário um deslocamento da episteme vigente para uma abordagem da matriz africana no seio da universidade, ou seja, desenvolver na formação docente estratégias que instrumentalizem para a promoção do legado cultural africano e da diáspora, identificar e desmascarar os conhecimentos eurocêntricos estabelecidos como universais, sem, no entanto, abrir mão de ensinar os conteúdos químicos já consagrados no currículo. ${ }^{8}$

Como desdobramento da referida Lei, as Diretrizes Curriculares Nacionais para a Educação das Relações Étnico-Raciais (DCNERER) e o Parecer CNE/CP 003/2004 versam sobre a reparação, o reconhecimento e a valorização da identidade, da cultura e da história dos negros brasileiros encaminhando que, para isso ocorrer, é necessário que se adote políticas educacionais e estratégias pedagógicas de valorização da diversidade e que se forme professores competentes no domínio dos conteúdos de ensino concomitantemente comprometidos com a educação de negros e brancos, no sentido de 
que venham a relacionar-se com respeito e empatia, sendo capazes de corrigir posturas, atitudes e palavras que impliquem em discriminação racial. ${ }^{9}$ As DCNERER traçam algumas metas nesse sentido, dentre as quais destacamos: "Proporcionar a nossos/as cidadãos/ãs a vivência de processos educativos que os levem a superar preconceitos raciais, a viverem práticas sociais livres de discriminação e que contribuem para seu engajamento em lutar por justiça social, étnica-racial."9

Esse rompimento com as epistemologias monocromáticas/racistas é desafiador e tem empenhado esforços já em algumas licenciaturas em química no Brasil. ${ }^{10}$ A temática tem sido tratada com vistas ao cumprimento dos pareceres, resoluções e orientações advindos da Lei 10.639/03 por meio de múltiplas estratégias e temas: objetos virtuais de aprendizagens, ${ }^{11-13}$ livros didáticos, ${ }^{14}$ direitos humanos, ${ }^{15}$ arte, ${ }^{16}$ música/poesia, ${ }^{17,18}$ protetores solares, ${ }^{19}$ ciclos econômicos do Brasil Colônia, como o do café, ${ }^{20,21}$ cana-de-açúcar ${ }^{22}$ e mineração, ${ }^{23-25}$ biocombustíveis, ${ }^{26}$ a química presente na noz de cola, ${ }^{27}$ no dendê, ${ }^{28} \mathrm{e}$ em outras plantas utilizadas em religiões de matriz africana, que foram tratados inter e trans disciplinarmente. ${ }^{10} \mathrm{~A}$ recomendação ainda tem sido contemplada com temas como a extração de platina na África do Sul, a exploração do Coltan na República Democrática do Congo e as produções científicas do antigo Egito. ${ }^{10}$

Tais estudos tem reiteradamente apontado que os conhecimentos científicos e tecnológicos dos povos africanos sofreram um apagamento e negação no processo histórico e essa sistemática dinâmica de desqualificação, deslegitimação e destruição da cultura negra justificando e legitimando a cultura do colonizador, nomeamos por epistemicídio. Um processo que nega, invalida, desautoriza, provocando ausências e silenciamentos de conhecimentos produzidos por grupos subalternizados como referenciais válidos, como fontes de conhecimentos e mais ainda, uma negação ontológica que incrementa o sentimento de inferioridade levando a uma forma patológica de ser e de se reconhecer. ${ }^{29}$

A imagem que nos é apresentada da África e de seus descendentes não está relacionada com sua produção intelectual nem com a tecnologia desses povos, mas ora com imagens de vida selvagem, ora com imagens degradantes de pessoas negras em situação de pobreza extrema. E isso sem que se discuta que o subdesenvolvimento do continente africano é fruto da exploração europeia, que também é necessário ser articulado qualificadamente para com os alunos e alunas. ${ }^{30}$ As contribuições dos povos africanos foram profundas, significativas e estão relacionadas a todas as áreas de conhecimento que nos mostram a riqueza das ciência, tecnologia e história dos africanos e da diápora. Dessa forma, valorizar o conhecimento produzido por negros e negras é fulcral para a sociedade antirracista preconizada pelas citadas políticas de estado, alcançadas a duras penas pelo movimento negro, a fim de reconhecer - em detrimento da imagem essencializada do negro como escravo, como crime, drogas e violência - a sua inteligência em empreender processos técnico-cientificos. ${ }^{31}$

Os antigos egípcios, por exemplo, criaram uma das primeiras mídias portáteis, o papiro e, não por acaso, Alexandria, cidade egípcia, tinha uma das maiores bibliotecas do mundo que sofreu vários incêndios criminosos que apagaram boa parte do legado do povo africano. ${ }^{32} \mathrm{Na}$ medicina, Imhontep, há quase $5000 \mathrm{mil}$ anos, desenvolveu os primórdios de diagnósticos e terapias, isso muito antes de Hipócratis (460 a.C. - 370 a.C) sequer ter andado na Terra. O Egito apresentava uma ciência médica e farmacológica organizada e bastante desenvolvida, e praticavam cirurgias complexas: cerebrais, de cataratas, ou engessamento de membros com ossos quebrados, conhecimentos de substâncias cicatrizantes e anestésicos. Em razão do desenvolvimento do processo de mumificação e, com isso, o acesso ao interior do corpo humano, os egípcios passaram a conhecer o sistema circulatório e o funcionamento de cada órgão e a relação entre eles. Ademais, a construção das pirâmides no antigo Egito é um exemplo da grande contribuição dada pelos povos africanos à engenharia, à arquitetura e à matemática. A tecnologia naval também já era desenvolvida a cerca de 2000 mil anos antes do suposto pioneirismo português. ${ }^{31}$

Frente ao apagamento dos conhecimentos africanos nos currículos escolares e a necessidade de efetivação da Lei 10.639/2003 nas escolas e universidades, advogamos por iniciativas para descolonizar o currículo e concordamos que "descolonizar é incluir o legado não visibilizado de culturas que compõem a formação da sociedade $e$ que foram suprimidos pelo eurocentrismo." ${ }^{33}$ Isso deve representar mudanças no projeto pedagógico do cursos de licenciatura em química que desembocam no ensino, pesquisa e extensão. À guisa de exemplo, na Universidade Federal de Goiás (UFG), o Coletivo Ciata do Laboratório de Pesquisas em Educação Química e Inclusão (LPEQI) do Instituto de Química tem desenvolvido (desde 2016) uma disciplina optativa na licenciatura com o objetivo de inserir aspectos teóricosmetodológicos que auxiliassem na implementação da educação para as relações étnico-raciais. A disciplina mobiliza saberes que dialogam com o objeto de conhecimento do curso, a saber o conhecimento químico, e participa aos professores em formação incial estratégias possíveis, material de apoio e os convoca a também à proposição. ${ }^{33}$

Na Universidade Federal do Reconcôvo da Bahia, o Grupo de Pesquisa, Ensino e Extensão em Educação Química (PEQUI) elaborou uma oficina pedagógica para alunos do último período do curso de licenciatura em química, para discutirem e refletirem sobre aspectos teóricos da Lei 10.639/2003 fazendo um levantamento sobre o conhecimentos dos licenciandos e licenciandas e apresentando a importância dessas discussões nas aulas de química para implementação da lei e de uma educação antirracista. ${ }^{34}$

Podemos afirmar que há avanços da inserção da temática educação para as relações étnico-raciais nas universidades e, mais especificamente, na formação docente em química. Dessa forma, neste artigo, nosso objetivo foi apresentar e discutir o percurso de inserção da temática em um curso de licenciatura em química em uma universidade pública estadual da Região CentroOeste. O estudo foi parte de um projeto maior de doutorado cuja investigação se deu na introdução da história e cultura africana em uma disciplina de núcleo específico e obrigatória da licenciatura da insituição. Nesse intento, no que se refere ao que foi tratado nesta comunicação, tivemos como objetivos específicos: refletir sobre o processo pedagógico de introdução da temática da Lei 10.639/2003 e da educação antirracista no currículo de formação inicial de professores e professoras de química do referido curso; analisar a operacionalização do deslocamento epistêmico no currículo da licenciatura a partir da temática "Egito Antigo, Cerveja e Química" de maneira a instrumentalizar os docentes e as docentes, participantes da pesquisa, para uma educação antirracista.

\section{METODOLOGIA}

O trabalho investigativo orientou-se por elementos de uma pesquisa-ação, que é por nós entendida como um tipo de pesquisa social com base empírica que é concebida e realizada em estreita associação com uma ação ou com a resolução de um problema coletivo no qual os pesquisadores e os participantes representativos da situação ou do problema estão envolvidos de modo cooperativo ou participativo (p.14). ${ }^{35} \mathrm{Um}$ dos principais objetivos dessa metodologia é dar aos pesquisadores e participantes os meios de se tornarem capazes de responder com maior eficiência aos problemas da situação. ${ }^{35}$ Dessa forma, nossa investigação foi sistematizada por intervenções pedagógicas (IPs) em ciclos espirais que objetivaram melhorar a prática docente, com enfoque no professor formador. 
Ponderamos que, nessa comunicação, IPs são por nós concebidas como

\section{pesquisas que envolvem o planejamento e a implementação de interferências (mudanças, inovações), destinadas a produzir avanços, melhorias, nos processos de aprendizagem dos sujeitos que delas participam, e a posterior avaliação dos efeitos dessas interferências tem como finalidade contribuir para a solução de problemas práticos (pp. 57-67). ${ }^{36}$}

Partindo da necessidade de se formar professores e professoras reflexivos e reflexivas em virtude de diversas mudanças ocorridas em nossa sociedade, exigindo desses profissionais inovação, para a qual é preciso uma transformação na postura, nas referências, no modo de planejar e executar a ação docente, principiando-se com uma formação crítico-reflexivo. A pesquisa-ação pode possibilitar ao profissional o estudo de sua própria prática pedagógica e a partir daí, atualizar-se frente às demandas que surgem a todo momento..$^{37,38}$

A pesquisa-ação ocorre em etapas por meio de ciclos espirais. Partindo do ciclo básico de uma investigação-ação, uma adaptação foi feita referente a este trabalho que ocorreu em dois ciclos com 5 fases da investigação-ação. Ponderando isso, o nosso trabalho se deu nas etapas descritas a seguir:

1) Observação: nossa investigação iniciou observando o Projeto Pedagógico do curso de Licenciatura em Química e foi constatado que este não apresentava atividades relacionadas à instrumentação para operacionalização da Lei 10.639/03 na formação inicial de professores, e verificamos a necessidade que os professores em formação inicial se apropriassem desse conhecimento para serem capcitados para a discussão a cerca de racismo em sala de aula e a proposta da referida Lei no ensino de química;

2) Planejamento: a partir do momento que foi detectado o problema, foram realizadas pesquisas bibliográficas que subsidiassem as professoras pesquisadoras na elaboração de materiais que abordassem conhecimentos/história de África e conhecimentos de química e, assim elaboradas as intervenções pedagógicas;

3) Ação: assim que as professoras pesquisadoras se apropriaram desses conhecimentos foi desenvolvida a ação planejada;

4) Avaliação: foi realizado um questionário logo após a apresentação da intervenção pedagógica (avaliação subjetiva e somatória) e outra avaliação no final do semestre na forma de seminário; para a nossa coleta de dados e posterior análise foi realizado o registro fílmico das intervenções;

5) Reflexão: momento de discutir e pensar sobre todas as etapas da investigação-ação, momento denominado de reflexão sobre a ação e reflexão sobre a reflexão na ação, no qual o professor e professora se tornam pesquisadores de sua própria prática, investigando sobre sua ação em busca de melhoria em sua prática para o ciclo porvir. ${ }^{38}$ Por motivo de espaço, neste artigo, apresentamos e discutimos apenas os resultados do primeiro ciclo de investigação-ação.

Os/as sujeitos da investigação (SI) foram 10 alunos/as, sendo 6 mulheres e 4 homens. Desses/as, 1 não respondeu, 2 se autodeclaram brancos, 5 pardos, 1 se autodeclarou moreno. Importa dizer, quanto à autodeclaração como "moreno", que a mesma representa a ideia criada tendo em vista o espectro cromático da negritude que, considerando a pigmentocracia estabelecida na sociedade racista, leva muitos não brancos a não se reconhecerem como negros, dado que representa uma série de preonceitos e discriminações a se enfrentar, além de que quanto mais clara a pele, há maior passibilidade. ${ }^{39}$

Esses SI foram identificados por A1 a A10, de uma turma do $7^{\circ}$ Período do Curso de Química Licenciatura em uma Instituição de
Ensino Superior (IES) na Região Centro-Oeste. Ainda foram sujeitos dessa investigação uma professora pesquisadora (PQ), atuante e militante no movimento negro, e uma professora formadora (PF) mulher negra, professora da citada IES, e em formação continuada como aluna de doutorado. A escolha da turma se deu por conta de PF ser a professora dessa turma na disciplina Prática de Ensino de Química 3 (PEQ3), com carga horária de 3 aulas/semana, totalizando 45h/semestre. A ementa da disciplina é apresentada no Quadro 1.

Quadro 1. Ementa da disciplina: Prática de Ensino de Química 3

\section{Objetivos:}

Objetivo geral:

Conhecer a importância, desafios e possibilidades da experimentação para a educação básica.

Objetivos específicos:

- Compreender e utilizar a experimentação na educação básica;

- Identificar e perceber quanto a importância, utilização da experimentação com o uso de materiais alternativos;

\section{Conteúdo programático:}

- Experimentação: desafios e possibilidades

- Segurança em laboratório de Ensino de Química;

- Tipos de atividades experimentais: suas funções e adequação;

- Experimentação com materiais alternativos;

- Análise, elaboração, reformulação e desenvolvimento de experimentos.

- Preparação de miniaulas na área de bioquímica.

\section{Estratégias:}

Aulas expositivas dialogadas, estudos dirigidos em sala, seminários em grupos ou individual, resolução de listas de exercícios, debates em salas, relatórios e trabalhos de pesquisa. Elaboração e apresentação de miniaulas com temas na área de bioquímica.

\section{Prática como componente curricular:}

As atividades desenvolvidas que fazem parte da prática como componente curricular nessa disciplina são: aprofundamento teórico e debates em sala sobre os conceitos trabalhados nessa disciplina e as fomas de abordagens no Ensino Médio. Análise de materiais didáticos e elaboração e apresentação de propostas didáticas para o Ensino Médio. Miniaulas e seminários que desenvolvam melhorias na postura, segurança e dicção do licenciando para atua como docente, assim como apropriação de conhecimentos relevantes para o docente em sala de aula do ensino médio.

Fonte: ref. 40.

Outro motivo para a escolha dessa disciplina se deu por ser obrigatória e específica da licenciatura. Mesmo que em seu ementário não trouxesse diretamente aspectos sobre a educação para as relações étnico-raciais, identificamos uma oportunidade de desenvolver aspectos teóricos e metodológicos que auxiliassem os/as sujeitos da investigação em sua formação, por meio da atividade de "prática como componente curricular" (PCC). Importa ressaltar que, de acordo com o projeto pedagógico do curso, a "prática como componente curricular, em cursos de licenciaturas, tem o papel de articular à formação específica da área de conhecimento, com situações práticas que subsidiem o futuro professor a exercer sua docência (p.76)". ${ }^{40}$

Ademais, o curso de Licenciatura em Química em seu Projeto Pedagógico de Curso (PPC) aponta como um dos temas transversais/ transversalidade o ensino da história da cultura afro-brasileira, tornando-o necessário em suas práticas pedagógicas. ${ }^{40}$ Ao incorporar os temas transversais no currículo do curso de Licenciatura em Química, nós buscamos fazer com que os alunos fossem capazes de compreender a complexidade da vida e a necessidade do respeito às especificidades. Dessa forma, como meio de trabalhar dentro da disciplina aspectos referentes à Lei 10.639/2003 e suas diretrizes, a PCC viabilizou a coleta de dados de nossa investigação.

A disciplina PEQ3, ocorre semestralmente e são 18 semanas de aulas por semestre. A disciplina transcorreu normalmente com o desenvolvimento dos conteúdos programáticos e durante esse período 
Quadro 2. Abordagem cultural e abordagem conceitual

\begin{tabular}{|l|l|l|}
\hline Assunto & Abordagem cultural de matriz africana & Abordagem conceitual - conhecimento científico \\
\hline Egito Antigo, Cerveja e Química & $\begin{array}{l}\text { A cerveja nas culturas africanas é mais do que apenas uma be- } \\
\text { bida, é um componente crítico para o desenvolvimento social, } \\
\text { estrutura econômica e política da sociedade (SILVA, 2013) }\end{array}$ & $\begin{array}{l}\text { Fermentação, processo de separação de mistura, } \\
\text { reaçoses químicas, composição da cerveja e suas } \\
\text { funçes. }\end{array}$ \\
\hline
\end{tabular}

Fonte: Adaptado da ref. 10.

foi reservado um dia (três aulas) para a apresentação da proposta de IP com a temática "Egito Antigo, Cerveja e Química". A IP foi planejada a partir de uma perspectiva de conceitos químicos por meio de uma abordagem cultural, conforme Quadro 2, com o objetivo de concretizar o que denominamos de deslocamento epistêmico.

Os dados foram coletados por intermédio de gravação em áudio que, em seguida, foi transcrita. A mesma foi feita com base no material empírico reproduzindo conversas reais, considerando os aspectos de entonação, da para-linguística e outros, seguindo a escrita e gramática padrão da língua, em que as/os falantes são indicados por letras no alfabeto. ${ }^{41}$

Os resultados foram analisados pela técnica de Análise da Conversação (AC) também chamada de estudos da fala em interação, que preocupa-se com a descrição das composições da conversação e suas estruturas organizadas. ${ }^{42} \mathrm{~A}$ AC é vista como uma interação naturalística. Dentro desse contexto, naturalística, indica que os dados foram coletados no ambiente em que eles aconteceram, ou seja, não são dados experimentais ou produzidos a partir de um roteiro prévio, não são coletados por meio de entrevistas pré-estipuladas, questionários, etc., mas em situações cotidianas e de maneira natural, mesmo que a pesquisa não fosse realizada. ${ }^{43}$

$\mathrm{Na}$ transcrição, os turnos de fala são enumerados de forma cronológica, representando cada um deles a intervenção de um sujeito na construção do diálogo. ${ }^{44}$ Cada IP produziu vários turnos de fala, que são construídos sequencialmente e reunidos por temas, chamados de tópicos discursivos. Desses tópicos, foram retiradas partes para análise e discussão que foram denominados de extratos, os quais foram escolhidos tendo como critério aqueles que possibilitassem uma discussão representativa dos objetivos desta pesquisa.

\section{RESULTADOS E DISCUSSÕES}

Com a intencionalidade de implementação da Lei 10.639/03, no curso de Química Licenciatura, foi desenvolvida uma IP que levantou discussões sobre produção de conhecimento da população africana, sua história e o legado atribuido a eles a partir de uma visão eurocêntrica e suas consequências nos dias atuais para os afrodescendentes. A seguir, apresentamos o plano da intervenção pedagógica no Quadro 3. A IP foi realizada no dia 12/11/2019, em duas aulas de 50 minutos com gravação em áudio de $1 \mathrm{~h} 20$ minutos.

A educação para relações étnico-raciais se efetivam quando saem do campo das palavras para a ação. Mas ação requer planejar: "pensar sobre aquilo que existe, sobre o que se quer alcançar, com que meio se pretende agir e como avaliar o que se pretende atingir (p. 21)." ${ }^{45}$ A licenciatura em questão, apesar de prever em seu projeto político pedagógico a temática racial, ela só se efetiva se os/as professores/as do curso planejarem e desenvolverem as intervenções necessárias. O plano da IP apresentada materializa a ação de uma professora incomodada com o atual estado de coisas que silencia espitemologicamente o grupo ao qual ela pertence.

O plano foi elaborado com a intenção de apresentar atividades que dialogassem com a realidade sociocultural brasileira, articulando saberes da ciência moderna com os conhecimentos produzidos por grupos historicamente excluídos dos curriculos escolares, os negros africanos. Assim, concretizamos a intencionalidade de
Quadro 3. Plano de aula da Intervenção Pedagógica Egito Antigo, Cerveja e Química

Objetivo da aula: Reconhecer a importância do legado africano a partir do contexto histórico da produção da cerveja egípcia; relacionar os conhecimentos dos keméticos com os conhecimentos químicos moderna e discutir a educação para as relaçõe étnico-raciais, a história e cultura africana e afro-brasileira com vistas ao deslocamento epistêmico no ensino de química.

Desenvolvimento: Em um primeiro momento da IP, foi instroduzida a discussão sobre o continente africano, específicamente sobre a localização do Egito e como sua população é vista aos olhos do mundo e discutimos um pouco sobre a invisibilidade e deslegitimação dos conhecimentos produzidos pelos africanos. Em um segundo momento, o debate apontou relações entre hegemonia, identidade e poder, o tratamento dado aos povos africanos, transformando-os em escravizados e vistos como inferiores destituídos de resistência ontológica e o apagamento de suas histórias dos currículos escolares. Em seguida, em um terceiro momento, buscou-se relacionar a história da produção da cerveja egípcia, os conhecimentos que o povo africano possuía com os conhecimentos da ciência moderna. E, finalizando a intervenção pedagógica, tivemos um quarto momento, em que foi oportunizado aos SI que falassem sobre a investigação-ação proposta para operacionalizar e instrumentalizar os professores em formação sobre abordagem para a educação para as relações étnico-raciais em sala de aula para o ensino médio.

Avaliação: questionário individual logo após a aula; avaliação em forma de seminário (final do semestre). Avaliações somativas.

Referência Bibliográfica

ALMEIDA, S. L. De. Racismo estrutural. São Paulo: Sueli Carneiro; Pólen, 2019.

BASTOS, M. A.; BENITE, A. M. C. Cultura africana e o ensino de Química: estudo sobre a formação docente. Revisa da ABPN, v. 9, nº 21, 2017. BENITE et al. Dai-me agô (licença) para falar de saberes tradicionais de matriz africana no ensino de química. Quim. Nova, vol. 42, $\mathrm{n}^{\circ} 5,570-$ 579, 2019.

FRANCISCO JUNIOR, W. E. Educação anti-racista: reflexões e contribuições possíveis do ensino de ciências e de alguns pensadores. Ciência \& Educação, v. 14, n 3, p. 398, 2008.

GOMES, N. L. Relações étnico-raciais, educação e descolonização dos currículos. Currículo sem Fronteiras, v. 12, nº 1, p. 98-109, jan/abril, 2012. MULLER, A. Cerveja. Canoas: Ed. Ulbra, 2002.

MUNANGA, K. Uma abordagem conceitual das noções de raça, racismo, identidade e etnia. Palestra proferida no $3^{\circ}$ Seminário Nacional das Relações Raciais e Educação - PENESB - RJ, 2003.

NASCIMENTO, E. L. (org.). A matriz africana do mundo. Sankofa I Matrizes Africanas da Cultura Brasileira. São Paulo: Selo Negro, 2008.

NELSON, D. L.; COX, M. M. Princípios de bioquímica de Lehninger. Artmed Editora, 2006.

ROSA, N. A. e AFONSO, J. C. A química da cerveja. Quím. Nova esc., vol. $37, \mathrm{n}^{\circ} 2$, p. 98-105, maio, 2015. RIBEIRO, D. O que é: lugar de fala? Belo Horizonte (MG): Letramento: Justificando, 2017.

SILVA, R. A. Isto não é Magia; é Tecnologia: subsídios para o estudo da cultura material e das transferências tecnológicas africanas 'num' novo mundo. São Paulo: Ferreavox, 2013.

VERRANGIA, D. Conhecimentos tradicionais de matriz africana e afrobrasileira no ensino de ciências: um grande desafio. Revista África e Africanidades, ano 2, $\mathrm{n}^{\circ}$ 8, fev, 2010.

desenvolver o deslocamento epistêmico no curriculo de formação docente, a partir da abordagem histórica e cultural da produção da cerveja egípcia e discutindo aspectos sociais e políticos (racismo, preconceito, discriminação, etc) em aulas de química, garantindo 
espaço a conhecimentos que foram silenciados pelos colonizadores por muito tempo. Destacamos também que os referenciais utilizados também caminham para essa direção: Munanga, Ribeiro, Gonzalez, Benite, Gomes, Francisco Junior, Verrangia, Almeida, entre outros presentes no plano.

As discussões sobre racismo em aulas de química se faz necessário, uma vez que todas as disciplinas tem papel relevante na criação de relações sociais éticas entre os/as estudantes. ${ }^{9}$ Sendo necessário formar professores reflexivos que reconheçam a rigidez dos currículos, a real história de constituição do país, romper com silêncios sobre a temática racial nas escolas/universidades, compreendendo a importância das lutas dos movimentos sociais, questionar a hierarquização de saberes como produto de uma classificação racial, entendendo que o conceito de raça é ideológico e históricamente usado para naturalizar as desigualdades e legitimar a segregação. A descolonização de currículos oportuniza aos sujeitos oprimidos o diálogo, ou seja, falar e o mais importante, ser ouvido, conhecer outras narrativas e levar para dentro das escolas e universidades práticas antirracistas, que valorizem a diversidade cultural. .,3,46 $^{2}$

A seguir, passamos à discussão de alguns extratos da intervenção pedagógica e reflexões correlatas. O primeiro momento da IP iniciou-se fazendo um levantamento sobre as ideias dos futuros docentes sobre o continente africano, especificamente sobre o Egito.

\section{Extrato 1- A invisibilidade do Egito negro}

T1 - PF: Eu vou falar da África como um todo, mas específico, vou falar um pouquinho sobre o Egito. [...] eu queria saber de vocês, quando a gente pensa Egito, fala a palavra Egito, o que é que vem à cabeça de vocês?

2 A1: iluminati

3 A2: pirâmide.

4 A3: Faraós, hebreus;

5 PF: $O$ que mais?

6 A4: Múmias

7 A5: Tom Cruise

8 A6: Alienígenas.

9 PF: Falar sobre o Egito, a gente pensa essas coisas, né? Vocês sabiam que o Egito fica na África?

10 A2: Fui descobrir esses dias, depois de muito tempo.

11 PP: Onde vocês achavam que ficava o Egito?

12 A1: Na Europa.

13 PF: Principalmente, por conta de filmes que a gente tem, e a gente sempre pensa em pessoas brancas.

14 A1: José do Egito (rsrs)

15 A2: Novela da Record, José do Egito, branco de olhos azuis.

Nos turnos 2, 3, 4, 6 e 8, estão as respostas dos SI a partir da questão levantada por PF em T1. E, como podemos observar as palavras levantadas pelos SI mostram que o processo de representação eurocêntrica do povo egípicio se deu de forma articulada, embranquecendo sua pele, apagando da história sua negritude e padronizando suas relações sociais pela visão europeia. A ideia desse Egito vem carregada de estereótipos que são muitas vezes produzidos e reproduzidos pela mídia, que insiste em apresentá-lo embranquecido e não pertencente ao continente africano, pois reconhecer as conquistas de um povo negro não corresponde à manutenção da hegemonia do poder à elite branca, especialmente no país como o Brasil erigido sobre a ideologia do branqueamento. Assim,

[...] seria mais seguro e mais sábio destituir o Egito, simples e muito discretamente, de todas as suas criações, em favor de uma nação realmente branca (a Grécia). Atribuir falsamente à Grécia os valores de um Egito supostamente branco revela uma profunda contradição, que não é a menos importante prova da origem negra do Egito (p. 66 e 67). ${ }^{8}$

Ainda sobre a destituição do Egito de sua própria história, no turno 8 , foi citada a palavra alienígena. A ideia de que foram seres de outro mundo que construíram as pirâmides do Egito, ganhou força em 1960, quando um escritor suiço, Erich Von D. Niken, afirmou em seu livro que nenhuma civilização antiga teria conhecimento técnico suficiente para erguer estrutura tão majestosa. Tal absurdo ainda permanece no imaginário das pessoas. Recentemente Elon Musk, CEO da Space X e da Tesla, levantou essa questão afirmando em suas redes sociais que foram os alienígenas que construíram as pirâmides do Egito, ou seja, sendo mais fácil atribuir esse feito à alienígenas do que dar crédito aos egípcios, aos negros. ${ }^{47}$

Sabemos que o Egito foi invadido por persas, gregos e romanos, e esses deixaram suas marcas e contribuições, fato que sempre acontece em todos os contatos entre civilizações. Mas isso não deve apagar as contribuições dos nativos na história dessas civilizações, como foi o caso na historiografia ocidental colonial, ao negar a origem negra da civilização egípcia como forma de justificar a colonização, a dominação e a exploração econômica de suas riquezas, como tática politica e ideológica de afastar o negro do processo civilizatório. ${ }^{48}$

No turno 7, A5 reportou o nome de um ator do cinema norte americano, Tom Cruise, talvez, por seu recente filme ser "A Múmia" (2017), associado ao Egito, fortalecendo a ideia de uma suposta raça branca que teria fundado o Egito. É comum que as produções hollywoodianas sempre embranqueçam a origem dos africanos, inserindo naturalmente artistas brancos como protagonistas, interpretando egípcios "legítimos", enquanto aos negros eram destinados a simples figurantes, invisibilizando a figura africana. ${ }^{32}$

É hora de resgatar a identidade do povo africano, uma vez que as produções televisivas, no que se incluem as novelas brasileiras, que são vistas pelos jovens, legitimam um Egito branco, mostrando os africanos como meros figurantes e coadjuvantes. É importante que o professor seja capaz de questionar essas situações e confrontar com a história, fomentando fatos reais para a discussão e levando os jovens para que analisem de forma crítica situações de racismo e exclusão do povo africano na contribuição histórica para a constituição do país e como isso afeta esses jovens em aceitar sua identidade. ${ }^{49}$ Conseguintemente, isso traz implicações para as licenciaturas, uma vez que torna-se imperioso discutir, neste contexto, o nível simbólico de extermínio do racismo, o epistemicídio, logo é preciso que os formadores de professores também se apropriem desses conceitos e discursos para desenvolvê-los com os docentes que atuarão na Educação Básica. Passamos à análise do extrato 2 intitulado: "Hegemonia, identidade e poder".

\section{Extrato 2- Hegemonia, identidade e poder}

30-PF: Qual o meu objetivo? Bom, a gente tem a matriz hegemônica, europeia, que é toda a visão de conhecimento a partir de um determinado povo, certo? Agora, será que só esse povo europeu que a gente vai ter que aprender a história deles, a cultura deles? Mas, quem ajudou na colonização aqui? Quem ajudou no começo? Na cultura? O Brasilfoi cultura de cana-de-açúcar, de café, quem é que trabalhava nessas culturas?

31-A1: escravos.

32 - PF: Quem eram esses escravizados?

$33-A 2$ : os negros.

34-PF: Os negros africanos, [...]. Então, foram trazidos da África, um monte de escravizados para o Brasil, eles trabalharam na lavoura de cana de açúcar, de café, nos garimpos de outro, muitas outras coisas, né? A gente fala que nós somos afrodescendentes, certo? 
35 - PF : Vocês se consideram afrodescendentes?

36-A3: Eu acho que sim

37-PF: Será? Isso é ruim pra vocês? Será que lá nos meus ancestrais tem algum africano, alguma pessoa escravizada?

38 - A1: não

39 - PF: Então, olha só, pelo censo do IBGE, o censo de 2010, fala que mais de $50 \%$ da população brasileira se autodeclaram preto/ pardo, então, imaginando que nossa população, mais da metade da população se autodeclara preto/pardo, então, qual é o meu intuito? Mostrar uma outra perspectiva, outro lado da história, pra que? Pra não imaginar que o negro africano e seus descendentes só carregam a historiografia de escravizados que a gente precisa sempre trabalhar em subemprego, você nunca vai ser um gerente, nunca vai ser uma empresaria, pela cor da sua pele. A minha ideia é mostrar que existe uma história, existem pessoas que fizeram coisas importantes e pra gente se espelhar nessas pessoas, pra dar hum, vamos dizer assim um respaldo, ou você sentir até orgulho de falar que é afrodescendente, que é negro/a0, [...]. A gente conhece o lado europeu da história, do conhecimento, agora eu quero mostrar o lado africano, o que eles têm para me mostrar [...] Eles fizeram muita coisa interessante que vale a pena se espelhar.

No turno 30, PF começou a discussão sobre a relação entre a disciplina de química e a Lei 10.639/03. Mesmo refroçando que a temática na Lei dirige-se às Artes, Lingua Portuguesa e História, importa dizer que o Art. 26a também indica que " $\$ 2 o$ Os conteúdos referentes à História e Cultura Afro-Brasileira serão ministrados no âmbito de todo o currículo escolar (grifo nosso), [...]." ${ }^{29}$ Ademais, concordamos que a sala de aula, notadamente, na aula de química não tem um fator especial que inibe o racismo (ou outros incovenientes sociais) de aparecerem, dessa forma, o docente deve estar preparado para as situações de racismo que nele acontecerão certamente, mas também qualificado para planejar e intervir no seu contexto. A ação deliberada do professor de química no atendimento à referida Lei depende de formação que agregue conceitos, linguagem, atitudes e, sobretudo, indignação com o racismo e suas manifestações.

Nossos resultados mostram no turno 30 várias questões que podem colocar os futuros docentes a refletirem a constituição histórica e cultural brasileria, uma história que não é conhecida. Os professores acabam tendo uma visão eurocentrista/monocultural, em que é naturalizada a invisibilidade do outro. Concordamos com Munanga, que é necessário abrir os olhos dos educadores para reconhecer a história do país que em que nasceram, a partir do contato das diferenças, da contribuição dos colonizadores europeus, dos indígenas e do africanos traficados violentamente para o Brasil. ${ }^{50}$

\section{Articulando os conhecimentos químicos}

No desenvolvimento desta IP foi discutida ainda a história da produção da cerveja a partir da perspectiva africana por meio do processo produtivo ancestral relacionando-o com o processo industrial. Assim, foi possível abordar a não linearidade da construção da ciência e tecnologia, em contraposição às narrativas do que encontramos nos livros didáticos, que são excertos de uma longa história, mas que não ocasionalmente omite o protagonismo negro. ${ }^{32}$ A partir dessa contextualização diversos conceitos químicos podem ser mobilizados: carboidratos, fermentação, entalpia de reação, solubilidade, etc.

A cerveja é fabricada através da fermentação alcoólica dos carboidratos presentes nos grãos de cereais como a cevada e o trigo. A fermentação refere-se à degradação anaeróbica da glicose ou de outros nutrientes orgânicos, em produtos variados, com o propósito de obtenção de energia. ${ }^{51}$ Esses conceitos podem ser problematizados articulando-se uma comparação entre técnicas atuais de produção cervejeira e o procedimento ancestral, destaca-se também o conceito de operações unitárias no estudo desses métodos de obtenção da cerveja.

Quais as diferenças? Quais as semelhanças? Que fatores implicam no método atual ser mais vantajoso comercialmente? Há riscos nesses processos atuais? Nisso, é possível relacionar a produção industrial de cerveja, seus procedimentos e riscos, inclusive por meio de casos reais. As cervejas artesanais produzidas pelos egípcios e as industriais têm princípios semelhantes como podemos verificar nas Figuras 1 e 2 .

A partir da relação entre a cerveja egípcia e a cerveja industrial, pode-se discutir o conhecimento químico necessário aos egípcios para a produção da cerveja, como o controle da temperatura na fermentação, o preparo do mosto, a explicação bioquímica do processo de maltagem, a adição de lúpulo e outras substâncias para agregar sabores diferenciados na cerveja (especificidades de métodos mais atuais). Desde o surgimento da cerveja no Egito antigo até os dias atuais, a técnica de preparo da cerveja passou por mudanças significativas. Hoje, de forma geral, a produção industrial da cerveja passa por sucessivas operações unitárias:

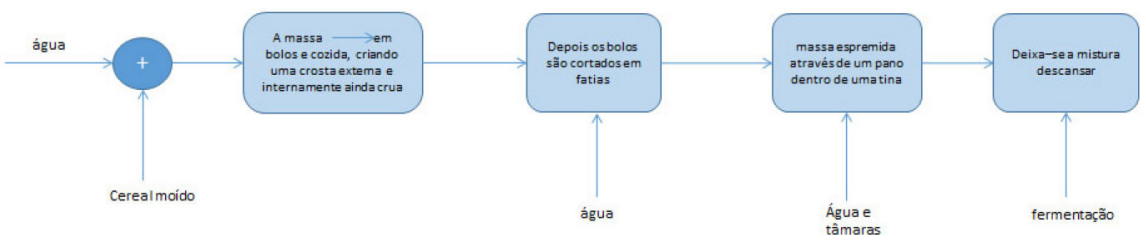

Figura 1. Receita Egípcia de cerveja, fluxograma adaptado da ref. 52

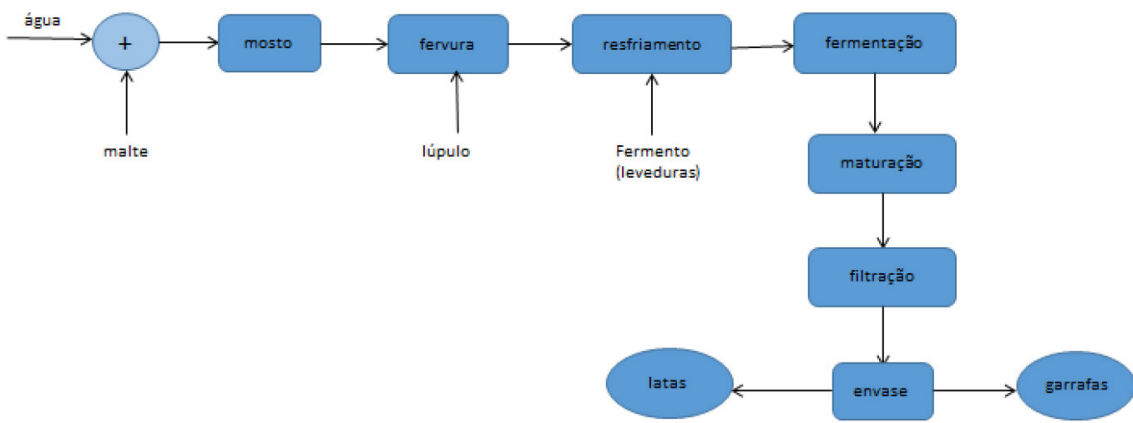

Figura 2. Processo industrial de produção de cerveja, fluxograma adaptado da ref. 53 
- Brassagem: primeira fase do processo: obtenção de uma mistura líquida açucarada, chamada mosto, que é a base para a futura cerveja. Nesta fase ocorrem várias etapas: moagem do malte, mistura com água, aquecimento para dissolução, filtração, adição do lúpulo, fervura do mosto pra dissolução e resfriamento;

- Fermentação: adição de leveduras (Saccharomyces cerevisiae). É importante o controle preciso da temperatura, em geral entre 10 e $25^{\circ} \mathrm{C}$,

- Maturação: a cerveja é resfriada a $0^{\circ} \mathrm{C}$. A levedura é separada por decantação (sedimentação), tem inicio a maturação. A maturação leva de 6 a 30 dias;

- Filtração: adiciona-se um material adsorvente chamado terra diatomácea, que tem a função de remover partículas em suspensão;

- Acabamento e envasamento: a cerveja recebe estabilizantes e antioxidantes. Passa por processo de pasteurização, aquecimento a $60-70^{\circ} \mathrm{C}$. A partir desse processo é possível estimar uma data de validade ao produto de seis meses após sua fabricação. ${ }^{53}$

Pode-se discutir cada etapa mostrando a presença do conhecimento químico e o porquê de cada ação e relacionar com a produção da cerveja pelos egípcios, que faziam uso procedimentos análogos. Ao se promover essa articulação, que não é fácil, ocorre o que têm sido sistematicamente negado às populações negras: contar-se sua história em ciência e tecnologia. Advogamos que tais ações pedagógicas podem deter a desvalorização da herança cultural africana e afrodescendente, ou seja, ensinar o conhecimento químico, relacionando a cultura científica à cultura africana e afrodescendente, incluindo conhecimentos antes invizibilizados no currículo escolar. ${ }^{54}$

Isso engendra algumas ações pedagógicas para aula de química como facilitadores da materizalização do deslocamento epistêmico. Nós sugerimos a via da experimentação. Os professores e professoras podem propor experimentos sobre fermentação de diferentes cereais com o objetivo de discutir se o processo fermentativo se comporta da mesma maneira para diferentes cereais e abordar explicações científicas para esses comportamentos, assim como, provocar debates sobre as semelhanças e diferenças entre o processo ancestral e o industrial contemporâneo. É possivel também a visitação planejada em uma indústria cervejeira local para que os alunos possam se engajar ainda mais nas discussões mobilizando os conceitos científicos envolvidos.

A partir dessas reflexões, no desenvolvimento da IP, os alunos foram instigados à pensar como o deslocamento epistemológico poderia ser concretizada no ensino médio. No Extrato 3 os turnos produzidos remetem à opinião dos licenciandos e licenciandas sobre essa problemática.

\section{Extrato 3 - Visão dos SI na abordagem da IP}

140 - PF: Vocês acham que funcionaria lá no ensino médio?

141 - A1: Eu acho que sim, professora, porque às vezes, a pessoa, se ela não tiver isso de dizer que ela consegue lá, ela não chegue nem aqui.

142 - A9: E lá, ela está começando e, se você incentivar ela, ela tem mais coragem de ir pra frente.

143 - A7: Eu acho assim, tipo assim, tem muita gente no ensino médio que tá muito cansada dessa química tradicional que a gente vê, que a gente acha muito difícil e complicada e acho que se aprender dessa forma, faria os alunos compreenderem, entender...

144 - A4: mas, lembrando que ...

145 - A9: falando do cotidiano deles.

146 - PF : Falando do cotidiano deles traria uma visão que é alguma coisa que, mesmo que eu fale que não quero vê esse lado, não sou negro, sou branco. Mas, mostrar que existe uma história por trás disso e não é uma história feia.

147 - A9: E também não ficar só no cotidiano, mas também explorar novos conhecimentos, novas perspectivas de lugares diferentes, de histórias diferentes, de contextos diferentes.

148 - A4: Só que é difícil agregar isso, assim, não é difícil pros alunos, eu to falando, eu to falando porque às vezes, os professores, vocês não podem ter essa liberdade de poder até mudar o jeito de dar aula. A minha irmã, por exemplo, os professores não dão aula, é só questão do Enem, eles passam matéria, mas eles, assim, o foco deles, lá do Colégio que ela estuda é o Enem, ela fala que muita coisa passa por cima, porque eles falam que não vai cair e passa direto.

149 - PF: E me digam, para a formação de professores, na ideia de vocês, enquanto futuros professores/as, vocês terem a oportunidade de observar que existem outras fontes de conhecimentos, vocês acham que pra vocês, para a formação de vocês, isto é alguma coisa válida? 150 - A7: Demais.

151 - A4: Demais

152 - A7: Eu mesma nem sabia que tinha essa divisão de matrizes. Nunca tinha ouvido ninguém falar isso.

153 - PF: A ideia é a gente mostrar que existe, existe, mas porque será que a gente não sabe? E, aí, porque a gente não fica sabendo dessas coisas? O que vocês acham?

154 A4: Professora, eu não sei porque a gente não fica sabendo, mas eu acho que dessa maneira aí, presta mais atenção, porque você levando pra eles uma história, é mais fácil eles...

155 - A7: Desperta a curiosidade.

156 - A4: Isso, eles conseguem, tipo, assimilar a história com o conteúdo, querendo ou não, porque alguma coisa vai ficar na mente.

No turno 140, a PF buscou saber a opinião dos SI sobre o tipo de abordagem apresentada com foco para os alunos do ensino médio. Nos turnos 141 e 142, os SI falaram da questão do incentivo, da valorização do outro de maneira que "as diferenças não devem ser transformadas em desigualdades, mas valorizadas em um contexto de respeito mútuo e bom convívio, pois enriquecem e enaltecem o meio cultural e a identidade nacional." Porém, o nosso país naturaliza o racismo, o legitima no dia a dia em que o ser negro está intimamente ligado ao ser pobre e duvidável. Ou seja, anunciando uma população inteira a ocupar um lugar à margem da sociedade..$^{55}$

No turno 143, A3 apoia a ideia de incorporar nos currículos a presença da historiografia e contribuição da população negra no ensino médio como uma forma de incentivar os alunos a permanecerem na escola. Nisso, concordamos que,

Com efeito, um sistema educacional que realmente pretende fornecer as bases para esse desenvolvimento precisa possibilitar aos seus estudantes o conhecimento do seu próprio povo, sob pena de não gerar nesses estudantes autoestima suficientes para fortalecê-los perante os desafios da vida, para a concretização dos empreendimentos para o desenvolvimento social (p.3). ${ }^{32}$

A representatividade positiva que a juventude negra tanto carece é possível nos currículos de ensino de ciências e tecnologias. No turno 146, a PF alertou que não está se tratando de alternativa voltada a um público específico da sala de aula, mas a todos e todas que a constitui. A educação para as relações étnico-raciais significa conhecer a história e cultura de povos que contribuíram pra construção do país, no caso de nossa investigação, os africanos. O que se pretende, portanto, é desconstruir visões depreciativas para se reconstruir relações horizontalizadas pelo respeito e pela empatia. Logo, a história do 
povo negro é importante não só para os estudantes de ascentralidade negra, mas para todos os alunos/as, especialmente de etnias brancas, pois estes apresentam uma educação carregada de preconceitos. E, além disso, a cultura presente em nosso país se deve a aglutinação de todas as etnias que contribuíram para o desenvolvimento social e econômico. ${ }^{56}$

Quando se fala de "resgate da memória coletiva e da história da comunidade" ${ }^{56}$ percebemos o quão importante é para toda a população brasileira que se faça esse resgate, se valorize essa história. Quando relacionamos conhecimentos científicos e saber tradicional, que são formas diferentes de investigar e compreender o mundo e produzir cultura, estamos estabelecendo diálogos entre essas comunidades, por exemplo, a partir do estudo sobre ervas e plantas medicinais de comunidades afro-brasileiras em aulas de química, com a intencionalidade de mostrar a contribuição da matriz africana, relacionando com o conhecimento científico, resgatando e valorizando esses conhecimentos para diminuir e combater a violência sofrida por essas comunidades. Essa mudança de foco poderia engajar os alunos na aprendizagem, fortalecendo a identidade negra e evitandose, assim, o epistemícidio. Pois a escola é o local de manutenção e difusão de conhecimentos. ${ }^{10}$

No turno 149, a PF indagou como os SI veem a abordagem apresentada, e nos turnos 150, 151 e 152, os SI responderam que foi válido, e que nunca antes tiveram acesso a discussões semelhantes. Nesse sentido, defendemos e concordamos que a introdução dessas reflexões e orientações na licencitura em química pode ser um passo imprescindível em que os docentes as reproduzam em suas ações locais favorencendo o combate ao racismo, valorizando a diversidade étnico-racial e promovendo conhecimentos adequados sobre história e cultura africana e afrodescendente. ${ }^{57}$

A educação das relações étnico-raciais é formada na dialética experiência/reflexão, sendo esta influenciada pelas ideologias dominantes e experiências dos futuros professores em toda sociedade. ${ }^{57}$ Por isso, concordamos que o conhecimento teórico e prático sobre a temática étnico-racial é fundamental para os professores e professoras em formação incial, mas não basta apenas inserir essa temática, precisamos de professores e professoras reflexivos e críticos de sua própria prática e da sociedade, de forma que se reconheçam como pertencentes a uma sociedade multirracial, e que se coloquem em um precurso formador e formativo em que as desigualdades sejam mitigadas e não mais obliteradas do debate ou mesmo inviesadas pelo mito da democracia racial. ${ }^{58}$

Dessa forma, os/as docentes devem adotar uma postura ética em favor da descolonização dos currículos a partir de práticas pedagógicas interculturais e antirracistas, negando discursos hegemônicos e monoculturais que silenciaram a importância da ascentralidade africana e a construção da identidade negra nos espaços escolares. ${ }^{58}$ Portanto, é de fundamental importância que os professores formadores/as tenham consciência da dimensão do processo educacional e tenham o domínio de literatura especializada, e não recorram às suas próprias convicções, refletindo sobre as diversas situações que o exercício da profissão apresenta, já que tudo dito pelo professor ou professsora, em sala de aula é formação. ${ }^{58}$

No turno 153, a PF comentou sobre o porquê de não sabermos da existência de outras fontes de conhecimentos, o que nos traz a questão da hegemonia europeia, do eurocentrismo, da manutenção do status quo apresentando outros povos como inferiores. E a manutenção disso está relacionado à única história que cria estereótipos, destitui uma pessoa/povo de sua dignidade e, se contada diversas vezes, reforça a ideia a que se pretende passar. E também está relacionada com o poder de quem conta, como se conta e quantas vezes essa mesma história é contada, até que se defina a história de um povo. Histórias são importantes, assim como cria sofismas sobre um povo, pode destacar e devolver a dignidade dele. ${ }^{59}$ Devemos, então, questionar àquelas contadas sobre pessoas e principalmente sobre um povo para que desfaçamos estereótipos e preconceitos e oportunizemos conhecer as várias histórias produzidas para e/por um povo.

A voz do professor de química pode e deve ser um meio pelo qual a história e a cultura negras chegam aos estudantes do ensino médio. A formação docente deveria proporcionar aos professores, portanto, saberes que os norteariam em sua prática docente para a descolonização do ensino de química. Quando não orientados sobre como desenvolver as estratégias que articulem raça, ciência (química, em nosso caso), é natural que os professores adotem alternativas seguras, ou nem tanto, vez que cada vez mais comuns são as cenas cenas de violências com quais nos deparamos em sala de aula e não dar uma resposta robusta a elas resulta em um cada vez maior número de situações-limite na sala de aula. ${ }^{60} \mathrm{O}$ enfrentamento do racismo e de outros incovenientes sociais não são problemas contornáveis, devemos agir.

Compreedemos, porém, que o caminho para esse enfetamento nos leva à possibilidade de errar, o que impõe desafio e insegurança. Defendemos que o percuso formativo ao professor de química, em vista disso, pode ser a reflexão sobre a reflexão na ação, cabendo ao professor e professora buscarem uma explicação para novas situações, se apropriar de novas teorias, dialogar com outras perspectivas, investigar situações, pesquisar, refletir e ser crítico de sua própria prática, se tornando um pesquisador e pesquisadora de sua práxis. ${ }^{38}$

Dessa forma, a construção de uma educação para as relações étnico raciais na formação docente requer uma mudança cultural e epistemológica, pois foram construídas historicamente em meio ao poder e das supostas hierarquias sociais, fortalencedo as desigualdades étnico-raciais em todos os setores da sociedade. ${ }^{61}$ Para que se efetive a educação das relações étnico-raciais, não é somente a inclusão de componentes curriculares nos cursos de licenciatura e de conteúdos no currículo da escola da educação básica, mas sim uma mudança na postura, no fazer pedagógico de cada docente e uma mudança no olhar sobre as pessoas negras, valorizando a história e a cultura do nosso povo.

\section{ALGUMAS CONSIDERAÇÕES}

A intervenção pedagógica sobre a temática "Egito Antigo, Cerveja e Química" trouxe a possibilidade de mostrar aos professores e professsoras em formação como articular conhecimentos químicos partindo de uma abordagem histórica, cultural africana, ou seja, apresentando outra narrativa de conhecimento contribuindo com a operacionalização da Lei 10.639/03 e isso acarretou em uma mudança epistemológica e pedagógica do professor formador, uma vez que ele precisou buscar rever toda sua formação acadêmica. Na investigação realizada, a proposta da mudança curricular ocorreu em uma disciplina obrigatória da grade curricular do curso de Licenciatura em Química, que não previa em seu ementário essa discussão. Todavia, foi possível realizar o deslocamento espistêmico incluindo atividades pedagógicas que dialogaram saberes da ciência moderna e os saberes dos povos africanos. Isso parece haver possibilitado que os professores e as professoras em formação inicial se instrumentalizassem e que fossem capazes de discutir em aulas de química aspectos inerentes à educação antirracista.

Identificamos a total ausência de informações sobre a história e cultura africana como fonte de produção de conhecimento e, especificamente a história e cultura egípcia, dos alunos e alunas em formação, mesmo estando no penúltimo período do curso. Isso nos leva a concluir que a temática apenas ocupa um lugar fictício no Projeto Pedagógico do Curso. Dessa forma, foi necessário alterar a abordagem da intervenção pedagógica e notamos que 
é necessário que o professor formador e a professora formadora façam diagnósticos para conhecerem os saberes dos alunos e alunas para assim estabeleceram suas formas específicas de deslocamento espitemológico.

A partir de nossos resultados, percebemos que a química pode contribuir para formação docente em uma prática antirracista discutindo conceitos químicos a partir de uma perspectiva histórica. Em nossa investigação, a Lei 10.639/2003 não se materializou sozinha, assim sendo, foi por meio da atuação da PF que a mesma saiu do projeto pedagógico do curso e concretizou-se na disciplina PEQ3 por meio da PCC. Destarte, urge a necessidade de mais ações como essa, em outras disciplinas da grade obrigatória do curso, para que ocorra a apropriação desses conhecimentos no ambiente acadêmico.

Para o ensino de química, essa investigação vem reiterar a necessidade de professores formadores nas universidades que busquem acrescer de forma qualificada o imperativo legal das diretrizes curriculares referentes à citada Lei nas licenciaturas em química. Para professora pesquisadora/formadora, mulher negra, socialmente invizibilizada, essa intervenção trouxe a oportunidade de romper silêncios em uma universidade pública, falando sobre racismo, discutindo relações étnico-raciais e diversidade cultural, propiciando uma educação antirrracista que buscou romper com o atual estado de coisas que afasta a juventude negra, de forma geral, da ciência e da tecnologia e, mais especificamente, da química.

\section{REFERÊNCIAS}

1. Francisco Júnior, W. E.; Ciência \& Educação 2008, 14, 397.

2. Almeida, S. L. de.; Racismo estrutural, $1^{\text {a }}$ ed., Pólen: São Paulo, 2019.

3. Ribeiro, D.; O que é lugar de fala?, $1^{a}$ ed., Letramento: Belo Horizonte, 2017.

4. Munanga, K.; $3^{o}$ Seminário Nacional das Relações Raciais e Educação, Rio de Janeiro, Brasil, 2003.

5. Silva, T. T.; Documento de identidade: uma introdução às teorias do currículo, $2^{\mathrm{a}}$ ed., Autêntica: Belo Horizonte, 2005.

6. Bastos, M. A.; Benite, A. M. C.; Revisa da ABPN 2017, 9, 64.

7. Santos, V. L. L.; Benite, A.M.C.; Revista da ABPN 2018, 10, 125.

8. A matriz africana do mundo. Sankofa I-Matrizes Africanas da Cultura Brasileira; Nascimento, E. L., org.; $1^{\text {a }}$ ed., Selo Negro: São Paulo, 2008.

9. https://download.inep.gov.br/publicacoes/diversas/temas interdisciplinares/diretrizes_curriculares_nacionais_para_a_educacao_ das_relacoes_etnico_raciais_e_para_o_ensino_de_historia_e_cultura afro_brasileira_e_africana.pdf, acessada em setembro 2021.

10. Benite, A. M. C.; Faustino, G. A. A.; Silva, J. P.; Benite, C. R. M.; Quim Nova. 2019, 42, 570.

11. Pinheiro, J. S.; Silva, R. M. G.; Anais do XIV Encontro Nacional de Ensino de Química, Curitiba, Brasil, 2008.

12. Pinheiro, J. S.; Dissertaçao de Mestrado, Universidade Federal de Uberlândia, Brasil, 2009.

13. Santos, E. S.; Rodrigues Filho, G.; Amauro, N. Q.; Atas do IX EncontroNacional de Pesquisa em Educaçao em Ciências, Águas de Lindóia, Brasil, 2013.

14. Pinheiro, J. S.; Henrique, H. C. R.; Santos, E. S.; Anais do XV Encontro Nacional de Ensino de Química, Brasília, Brasil, 2010.

15. Dionysio, R. B.; Amorim, G. C.; Oliveira, R. D. V. L.; Revista Práxis 2015, 14, 63 .

16. Silva, E. M. S.; Francisco Júnior, W. E.; Quim. Nova Esc. 2018, 40, 79.

17. Francisco Júnior, W. E.; Silva, E. M. S.; Yamashita, M.; Atas do IX Encontro Nacional de Pesquisa em Educaçao em Ciências, Águas de Lindóia, Brasil, 2013.

18. Santos, R. G.; Siemsen, G. H.; Silva, C. S.; Atas do IX Encontro Nacional de Pesquisa em Educaçao em Ciências, Águas de Lindóia, Brasil, 2015.
19. Vargas, R. N.; Faustino, G. A. A.; Fernandes, F. S.; Benite, A. M. C.; Ser Social 2018, 20, 348.

20. Santos, A. B.; Moura, V. C. T.; Moreira, P. F. S. D.; Anais do XVIII Encontro Nacional de Ensino de Química, Florianópolis, Brasil, 2016.

21. Bastos, M. A.; Amauro, N. Q; Benite, A. M. C.; Revista da ABPN 2017, 9, 312 .

22. Bastos, M. A; A. M. C.; Revista da ABPN 2017, 9, 64.

23. Benite, A. M. C.; Bastos, M. A.; Camargo, M. J. R.; Vargas, R. N.; Lima, G, L. M.; Benite, C. R. M.; Quim. Nova Esc. 2017, 39, 131.

24. Benite, A. M. C.; Silva, J. P.; Alvino, A. C.; Educaçao em Foco 2017, 21,735 .

25. Silva, J. P.; Benite, A. M. C.; Revista da ABPN 2017, 9, 273.

26. Lima, G. L. M.; Alvino, A. C. B.; Moreira, M. B.; Silva, J. P.; Moura, A. R.; Silva, A. G.; Faustino, G. A. A.; Bastos, M. A.; Benite, A. M. C.; Anais do XVIII Encontro Nacional de Ensino de Química, Florianópolis, Brasil, 2016.

27. Moreira, P. F. S. D.; Rodrigues Filho, G.; Fusconi, R.; Jacobucci, D. F. C.; Quim. Nova Esc. 2011, 33, 85.

28. Silva, J. S.; Alvino, A. C. B.; Santos, M. A.; Santos, V. L.; Benite, A. M. C.; Quim. Nova Esc. 2017, 39, 19.

29. Carneiro, A. S. Tese de Doutorado, Universidade de São Paulo, Feusp, Brasil, 2005.

30. Coutinho, A. C. P. C.; Barreiros, D. K.; Silva, G. P.; Stoppa, G. C.; Gonçalves, R.; Melo, V. A.; Araújo, V. P. C.; Cadernos da Pedagogia 2008, 2,74 .

31. http://smec.salvador.ba.gov.br/documentos/contribuicao-povos-africanos. pdf, acessado em setembro de 2020.

32. Silva, L. H., Pinheiro, B. C. S.; RedeQuim - Revista Debates em Ensino de Química 2018, 4, 5.

33. Camargo, M. J. R.; Benite, A. M. C.; Quim. Nova 2019, 42, 691.

34. Conceição, L. F.; Gois, L. S.; Lima, R. S.; Revista Insignare Scientia 2020, 3, 137.

35. Thiollent, M.; Metodologia da pesquisa-ação, $2^{\mathrm{a}}$ ed., Cortez: São Paulo, 1986.

36. Damiani, M. F.; Rochefort, R. S.; Castro, R. F.; Dariz, M. R.; Pinheiro, S. S.; Caderno de Educação 2013, 45, 57.

37. Feitosa, R. A; Dias, A. M. I.; Em 20 anos sem Donald Schon: o que aconteceu com o professor reflexivo?; Shigunov Neto, A., Fortunato, I., orgs.; Hipótese: São Paulo, 2017.

38. Pimenta, S. G.; Em Professor reflexivo no Brasil gênese e crítica de um conceito; Pimenta, S. G.; Ghedin, E., orgs.; $7^{\mathrm{a}}$ ed., Cortez: São Paulo, 2012 , cap. 1.

39. https://www.geledes.org.br/me-descobri-negra-aos-67-anos/, acessado em setembro 2021.

40. Universidade Estadual de Goiás, U.E.G., 2015.

41. Marcuschi, L. A.; Análise da Conversação, $5^{\mathrm{a}}$ ed., Ática: São Paulo, 2003.

42. Gonçalves, A. T. P.; Administração: Ensino e Pesquisa 2016, 17, 273.6.

43. Silva, C. R.; Andrade, D. N. P.; Ostermann, A. C.; ReVel 2009, 7, 1.

44. Marcuschi, L. A.; Análise da Conversação, $18^{\mathrm{a}}$ ed.; Ática: São Paulo, 1986.

45. Menegolla, M.; Sant'anna, I. M.; Por que planejar? Como planejar? Currículo-Área-Aula, 12 a ed.; Vozes: Petrópolis, 2002.

46. Gomes, N. L.; Currículo sem Fronteiras 2012, 12, 98.

47. https://www.correiobraziliense.com.br/app/noticia/ciencia-esaude/2020/08/03/interna_ciencia_saude,878110/alucinacao-elonmusk-cria-revolta-ao-dizer-que-ets-construiram-pira.shtml, acessada em setembro 2021.

48. Munanga, K.; Origens africanas do Brasil contemporâneo: Histórias, línguas, culturas e civilizações, Global: São Paulo, 2009.

49. Silvério, V. R. Em Síntese da coleção História Geral da África: Préhistória ao século XVI; Rocha, M. C., Rincón, M. B., Barbosa, M. S., eds.; UNESCO: Brasil, 2013, Introdução. 
50. Gonçalves, L. R. D.; Revista Educação e Políticas em Debate 2013, 2, 01.

51. Nelson, D. L.; Cox, M. M.; Princípios de bioquímica de Lehninger, $4^{\mathrm{a}}$ ed., Sarvier: São Paulo, 2006

52. Müller, A. Cerveja, Ed. Ulbra: Canoas, 2002.

53. Rosa, N. A.; Afonso, J. C.; Quim. Nova Esc. 2015, 37, 98.

54. Camargo, M. J. R.; Dissertação de Mestrado, Universidade Federal de Goiás, Brasil, 2018.

55. https://revistaeducacao.com.br/2020/06/23/educacao-antirracista/, acessado em setembro 2021.

56. Munanga, K.; Superando o racismo na escola, $2^{\mathrm{a}}$ ed., MEC/ Secad: Brasília, 2005.
57. Verrangia, D.; Interacções 2014, 31, 2.

58. Marques, E. P. S.; de Almeida, F. A.; da Silva, W. S.; Marques, H. S. Em Educação das relações étnico-raciais. Caminhos para a descolonização do currículo escolar; Marques, E. P. S., Troquez, M. C. C., orgs.; $1^{\mathrm{a}}$ ed., Apris: Curitiba, 2018, cap. 1

59. https://papodehomem.com.br/o-perigo-de-uma-unica-historia/, acessado em setembro 2021

60. https://periodicos.ufjf.br/index.php/edufoco/article/view/19657, acessado em setembro 2021

61. Fernandes, K. M.; Em Descolonizando saberes. A Lei 10.639/2003 no ensino de ciências; Pinheiro, B. C. S., Rosa, K., orgs., Livraria da Física: São Paulo, 2018, cap. 5. 